\title{
Design of Roof Cover Structures by Help of Numerical Models Defined in Formian
}

\author{
Janusz Rebielak \\ Faculty of Architecture, Cracow University of Technology, Kraków 31-155, Poland
}

\begin{abstract}
Numerical models defined by means of a suitably assumed set of parameters make it possible to select the optimal structural solution for the given or assumed conditions. The paper presents examples of applications of numerical models defined in the programming language Formian during the shaping processes of various types of spatial structural systems designed for roof covers. These types of numerical models can be relatively easily adapted to the requirements, which can be frequently changed during the investment process, what makes possible a considerable reducing of costs and time of design of the space structures having even the very complex shapes. The advantageous features of application of numerical models defined in Formian are presented in models determined for selected forms of the roof covers designed also by means of a simple type of a space frame. In the paper, there are some presented visualizations made on bases of these models defining mainly for structural systems developed recently by the author for certain types of the dome covers. The proposed structural systems are built by means of the successive spatial hoops or they are created as unique forms of the geodesic dome structures.
\end{abstract}

Key words: Numerical model, programming language, tension-strut structure, roof structure, dome cover.

\section{Introduction}

Space structures which belong to modern types of structural systems are widely applied in modern architecture and in the contemporary civil engineering. They mostly consist of a big number of component parts arranged in a uniform way located in spaces of these statically indeterminate systems, which implies that the structural design of them is a complex task. The application of suitable numerical models enormously accelerates the structural analyses and the entire investment procedures. During the design process of a building, it is necessary to change, sometimes quite often, the general shape or the details of its support structure. Therefore, it is advantageous when the defined numerical models of a considered structural system could be easily adjusted for the frequently changing requirements. The programming language Formian was invented with the aim to be

Corresponding author: Janusz Rebielak, Ph.D., professor, research fields: architecture, numerical methods of shaping and design of the space structures, methods of static calculations, lightweight structures for large span roofs, tall buildings and foundation systems. E-mail: j.rebielak@wp.pl. such a design tool, which will make easier and more effective the cooperation between all participants in the design process. It is based on simple principles of formex algebra invented by Nooshin [1] and Nooshin et al. [2], and it has the possibility to define the numerical models by means of broad sets of parameters optionally declared by the programmer according to the needs of current stage of the design. Due to such parameters, these models can be fluently and precisely adjusted to the conditions for rapid and numerous modifications of the investigated structural system. Numerical models defined in this way can be a basis for the further and comprehensively structural analyses carried out by application of, e.g., the finite element method [3] or other suitable methods [4, 5].

\section{Example of Simple Structural System and Its Numerical Model}

One of the simplest and the most frequently used forms of a space frame is called the "square on square" [4]. This double-layer space structure is usually built by means of struts having the same 
lengths and creating a solid system composed of a tetrahedron and half of an octahedron (Fig. 1).

In the formex algebra, a structural configuration is defined according to its position towards three basic directions $U 1, U 2$ and $U 3$, which may be considered as suitable counterparts to axes $X, Y$ and $Z$ in the three-dimensional Cartesian system. Precise description of rules of formex algebra and Formian functions are presented in Refs. [6-8]. Lines parallel to these basic directions are called "normat lines" and points of their intersections are called "normat points". Distances between these "normat lines" can be individually assumed by the programmer.

In the example presented in Fig. 2, these distances are assumed as a unity. In the formex algebra, for instance, position of Node $\mathrm{C}$ placed in the lower layer is defined by three successive figures separated by colons and put inside square brackets like as follows: $[1,1,0]$; a member of the upper layer located between Nodes A and B, comparing Fig. 2, is defined as: [2, 2, $1 ; 4,2,1]$, where the third coordinate indicates position of the lower or upper layer measured along the third direction U3. Member CD placed in the lower layer is defined as: $[1,1,0 ; 3,1,0]$, while the cross brace $\mathrm{AD}$ is described as: $[2,2,1 ; 3,1,0]$. Scale of advantageous characteristics of numerical models determined in the programming language Formian may represent those, which are defined in the program called Program 1 (full text of which is given in Appendix A). Numbering of rows is forbidden in

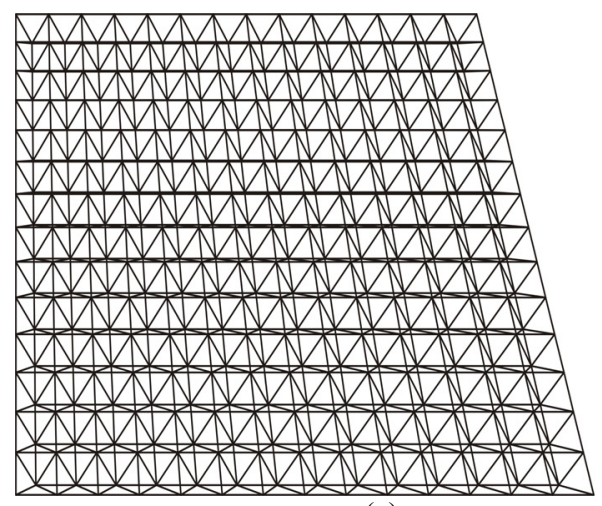

(a)
Formian but for a clear presentation of the program's structure, they are put as bold only because of technical reasons of this publication.

The flat form of this double-layer spatial structure

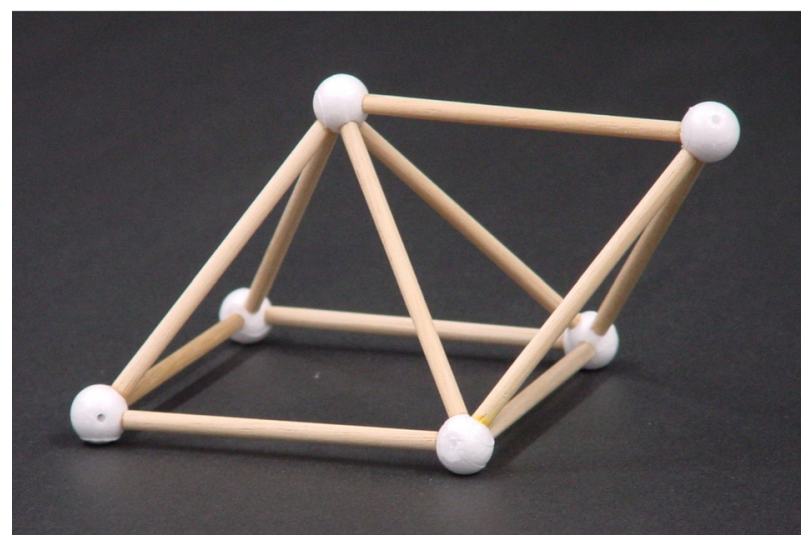

Fig. 1 Physical model of the solid strut set of the space truss called "square on square".

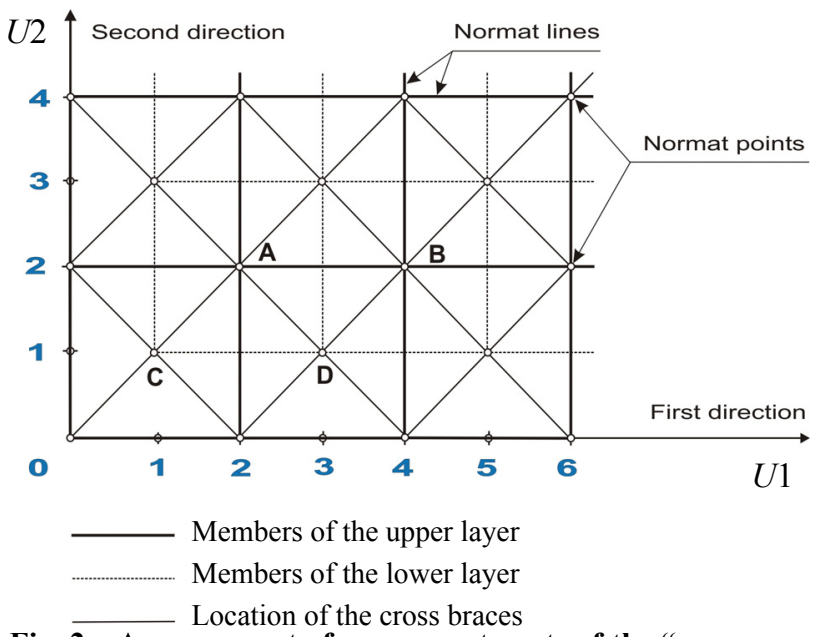

Fig. 2 Arrangement of component parts of the "square on square" space truss within the coordinate system applied in the programming language Formian.

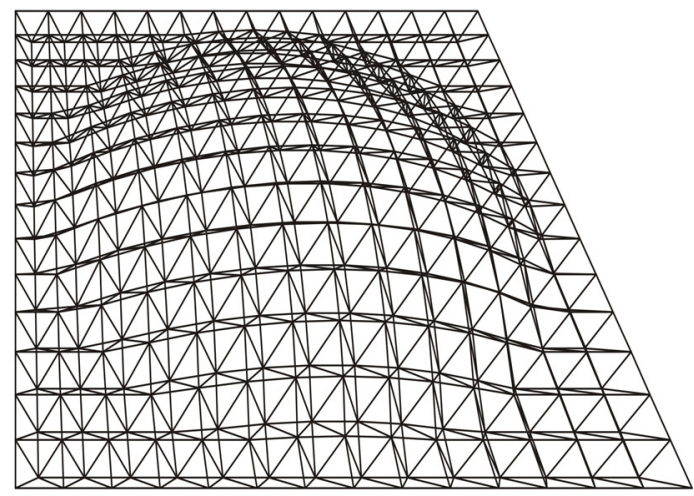

(b)

Fig. 3 Visualizations of numerical models defined in Formian for an example of: (a) a flat; (b) a complex form of the space truss called "square on square". 
is finally defined in Row a11 and its visualization is shown in Fig. 3a. Geometrical horizontal dimensions of the structure are determined by the values of parameters " $m$ " and " $n$ " defining number of replications of an assumed unit along, respectively, $U 1$ and $U 2$ directions. A numerical model of this structure is suitably transformed to model of a dome cover by means of special Formian's function "capel" described in Ref. [9], and the application of which suitably transforms its basic flat shape to the specific and complex form of the cover shown in Fig. 3b. The rise of the dome is controlled by the value of the parameter given as the last one inside the brackets (Row a15) of the "capel" function. Other parameters like the type of roof surface, coordinates of the sphere centre and clear span of the designed dome cover are defined by values of the four successive parameters put before the parameter mentioned above. This example can testify how useful the simple Formian's programs are for defining numerical models of even the very complex spatial structures. Mode and type of visualization of the just defined numerical model is determined in Row a16.

Numerical models of the various types of geometry of the dome structures can be defined in an equally simple way in Formian. It can be presented as an example of the basic space frame "square on square", designed as a double-layer dome structure of the meridian-parallel arrangement for the main component parts (Fig. 4).

For this purpose, the "basispherical retronorm" Formian function should be applied. The numerical model of the space frame of an assumed density of subdivisions has to be appropriately located in the three-dimensional space, orientated by positive senses of main directions $U 1, U 2$ and $U 3$ (Fig. 4a), then it can be precisely put onto the designed spherical surface (Fig. 4b), according to the compatible system of positive senses of the main directions (Fig. 4c), assumed for this surface in the programming language.

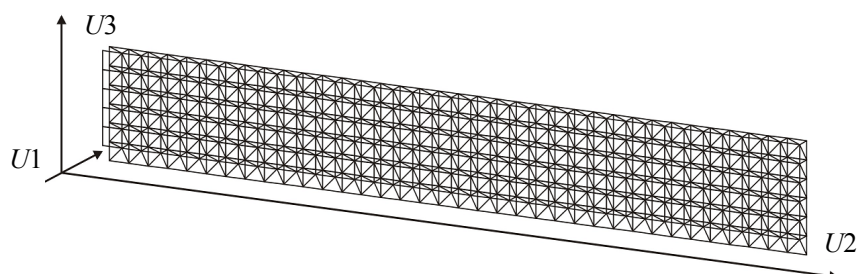

(a)

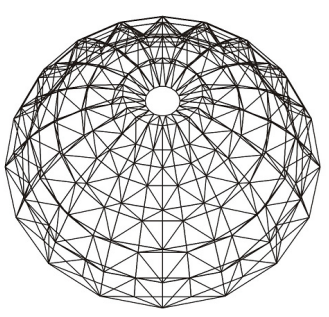

(b)

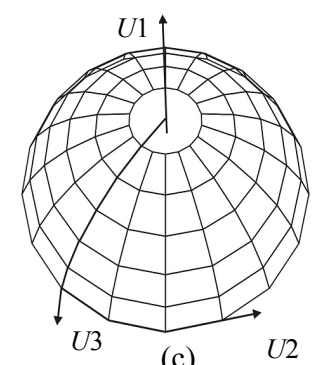

(c)
Fig. 4 Schemes of localizations of components of numerical model in space of the designed basic form of the truss system used in a specific "basispherical retronorm" of the programming language Formian: (a) a flat form of the basic structure located in space defined by coordinate system $U 1, U 2$ and $U 3$; (b) spherical form of the basic structure; (c) arrangement of directions of coordinates $U 1$, $U 2$ and $U 3$ onto the sphere surface in "basispherical retronorm".

\section{Numerical Model of the Crystal Tension-Strut Space Structure}

Economic reasons cause that dome covers of very large spans should be of small rises. This is dictated by the tendency to reduce the maintenance costs connected mainly with costs of heating or cooling of the huge volume of inner spaces of such buildings. Conventional types of structural systems do not allow the construction of domes of the desired small rises. Modern types of lightweight tension-strut structural systems are contemporary considered as a very efficient solution of this difficult technical task. The first systems of this type successfully applied in the practice were designed by W. Zalewski and D. Geiger, what is presented by Allen et al. [10], Robbin [11] and Geiger et al. [12]. The proposed form of the crystal tension-strut structure was invented by the author as result of suitable transformation of the previous appropriately shaped spherical form of the crystal space frame [13-15]. This new structural system 
mainly consists of tension members and a relatively small number of compression members (Cm) (Fig. 5).

These last members constitute the cross braces of the successive concentric hoops and a single vertical crown member of this dome system. All the components are suitably connected together and built in this way as the appropriately pre-stressed tension-strut structure, which has to be joined to the compression perimeter ring (R). The geometry of this system has a big impact on the structural features of the tension-strut structure. The sloping of the skew tension members ( $\mathrm{S}$ ) should not be too small. If it is less than $15^{\circ}$, then the values of the forces occurred in all members of the whole structure and value of the necessary pre-stressing of the whole system are of enormously large sizes [15]. A triangular grid of tension members of the upper layer makes the system more stable under the non-uniform application of the load than other structures of this type. The cladding system is usually designed in the form of membrane triangular sheets arranged between members of this layer. Each of the concentric hoops can be easily assembled at ground level, then in a quite simple way, these hoops can be hoisted one by one to the designed positions and jointed to the rest of the constructed structure by means of a set of the suitable tension members. All of the mentioned features suggest that the proposed crystal tension-strut structure could be a competitive technical solution to other systems of this kind. A numerical model of the proposed structural configuration was defined by means of Program 2

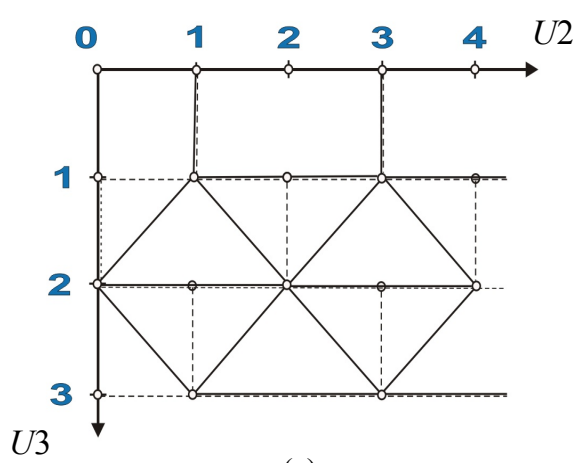

presented in Appendix B on the basis of the assumed schemes of arrangement of component parts in space of the crystal tension-strut structure as shown in Fig. 6.

The density of the structural subdivisions is controlled by means of two parameters " $n$ " and " $m$ " of the optional positive values of the both integers.

The listed Program 2 can be considerably shorter, but it was also decided to take into consideration the membrane panels located in the upper layer, positions of which are defined in rows between Rows b12 and b23. The main "basispherical retronorm" function is determined in Row b26. A visualization of execution of Program 2, in form which appears on the computer's screen, is displayed in Fig. 7. Panels of the membranes are presented only on the half of the upper layer in order to render the real structural configuration

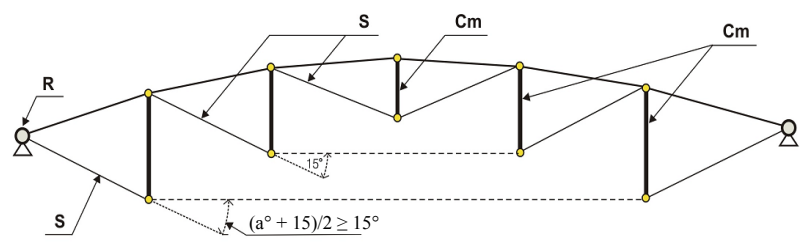

(a)

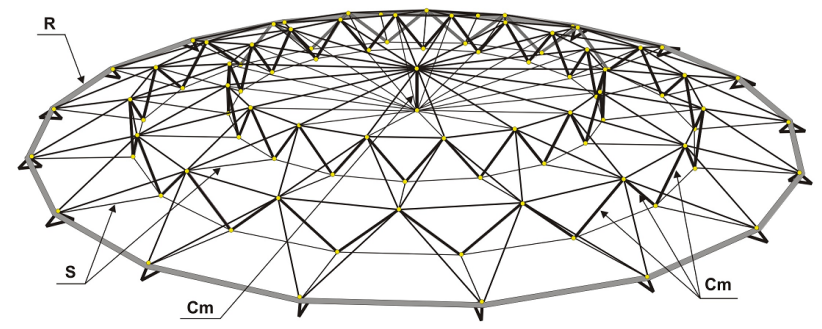

(b)

Fig. 5 Schemes of configuration of the system called the crystal tension-strut structure: (a) scheme of vertical cross-section; (b) general view of the structure.

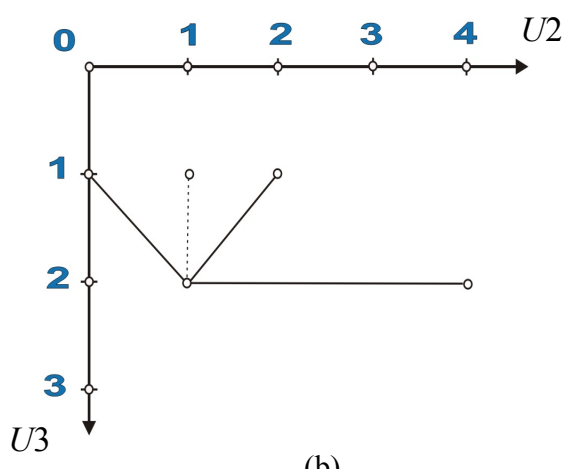

(b)

Fig. 6 Arrangements of component parts applied for defining numerical model of the crystal tension-strut structure in Program 2: (a) scheme of the central part; (b) scheme of the boundary area. 


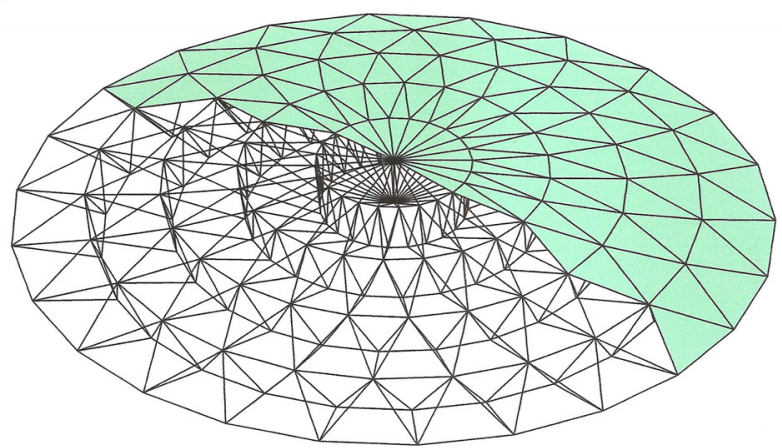

Fig. 7 Visualization of numerical model of the crystal tension-strut structure defined by means of Program 2.

of the system of the crystal tension-strut structure.

In Program 2, some Formian's cardinal functions were used. For instance, in Row b5, the so-called "rindle" function was applied, which enables replications of a numerical argument along direction indicated by the figure to put as the first inside brackets, the assumed number of replications is given by the value of parameter " $m$ ", where amount of translation at each step of replication is given by the third figure located between brackets. Another example of the cardinal functions called the reflection function (ref) is applied in Row b19. The direction of reflection is defined by two parameters inside the brackets, where the first one indicates one of the three main directions (U1, U2 or $U 3)$ and the second one defines position of the plane of reflection. There are some other cardinal functions of Formian applied in this program. In Row b25, the so-called "basipolar retronomic" function is applied, which enables to adjust a straight structural configuration to the appropriate concentric coordinates. This function is compatible with the "basispherical retronorm" function defined in Row b26 and it is necessary for defining the number of a spherical structure composed of successive horizontal hoops. Closer descriptions of both of these functions are presented in Refs. [2, 6, 7].

\section{Visualizations of Numerical Models of Selected Structural Systems}

The crystal tension-strut structure was subjected to numerous other transformations carried out in order to design a wide scope of structural forms of the lightweight bearing systems, possibly for application in different types of roof covers. In the processes of shaping the other types of the structural system, it was assumed to apply a repeatable unit in the form of the tetrahedron module, which was arranged in spaces of the created structures in various ways.

\subsection{Numerical Model of the VU-TensZ1gO Structure}

Numerous group of structural systems obtained in these shaping processes can be represented by two selected examples of spatial tension-strut structures.

The first one called the VU-TensZ1gO structure, general schemes of which are shown in Fig. 8, is shaped on the basis of the crystal tension-strut structure by means of the tetrahedron modules spaced alternately over the upper triangular fields of each concentric hoop. Numerical model of this type of structural system is defined by means of Program 3 (Appendix C), which is prepared on the basis of scheme of arrangement of component parts in space of this structure presented in Fig. 9.

Vertices of half number of these tetrahedrons are directed towards the perimeter ring while vertices of the second half of these modules are directed towards

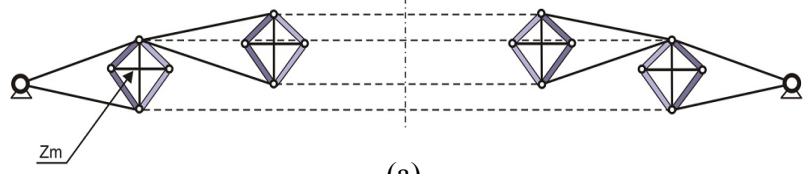

(a)

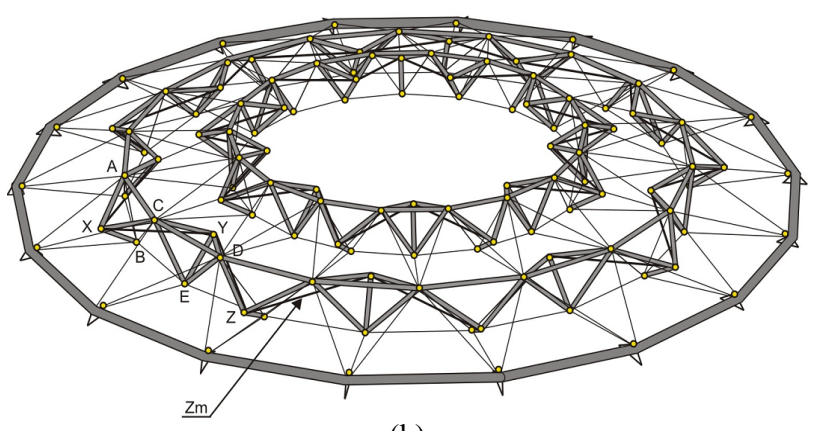

(b)

Fig. 8 Arrangement of component parts inside the space of a spherical form of the VU-TensZ1gO tension-strut system: (a) scheme of vertical cross-section; (b) view of arrangement of component parts inside the space of a spherical form of the VU-TensZ1gO tension-strut system. 


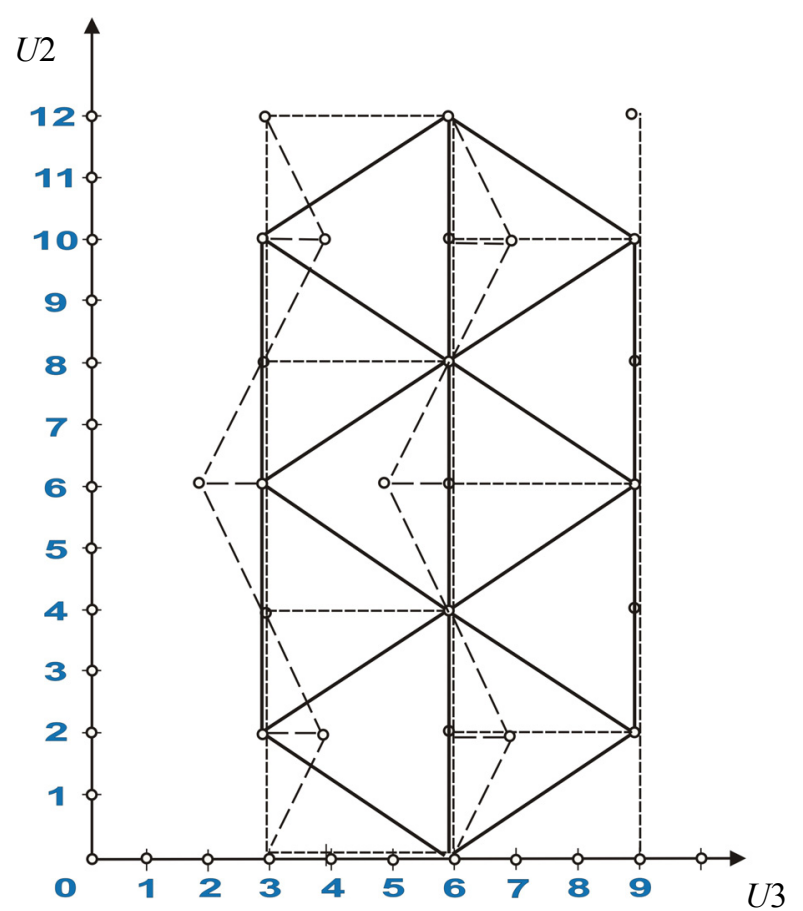

Fig. 9 Scheme of arrangement of component parts in space of the VU-TensZ1gO tension-strut structure applied for preparation of Program 3.

the dome centre. All the vertex nodes are connected together by means of tension members $(\mathrm{Zm})$ running along a broken line in the middle of a particular hoop.

The upper chords of these hoops are designed as struts which should make easier the assembly process of the whole structural system. The leading principle during the first stage of shaping was to obtain the most lightweight type of system called the VU-TensZ1gO structure [15]. If all cross members inside the concentric hoops are the tension members, then the values of the necessary pre-stressing have to be very big. This leads to a significant increase of the forces acting on all members which creates a significant increase in the weight of the whole structure. Process of the force transmission between all these components is more effective when the edges of bases of the tetrahedron modules are directed towards the dome centre, for instance, Segments CE and ED have to be made as struts (Fig. 8). This is a modified form of the VU-TensZ1gO structure which can be an economic system for dome covers with big central openings.
In Program 3, some other Forman's cardinal functions are applied. For instance in Row c21, one can notice a specific "basitrifect retronorm", which enables to define suitable co-ordinates of an object in the three-dimensional space. In Row $\mathrm{c} 22$, the "basipolar retronomic" function is applied, which enables in a convenient conversion of Cartesian coordinate system to the concentric configuration. In Row c23, one can notice again application of the "capel" function. The shape of Program 3 represents another way of defining in Formian the numerical models of the spherical systems composed of concentric structural hoops. Due to appropriately assumed parameters and application of the "capel" function, the rise of the dome cover can be fluently adjusted to the design requirements.

\subsection{Numerical Model of Geodesic Form of the VA(TH)No2 Tension-Strut Structure}

The second type of the proposed forms of bearing systems is shaped by the other structural concept of arrangement of the tetrahedron modules. The VA(TH) group of the tension-strut structures is created by means of these modules arranged respectively above and below triangular fields of the triangular-hexagonal grid of struts being the middle layer of these structures $[16,17]$. Half number of these modules have vertices directed up and put over each second of triangular fields of the grid, for instance, over the triangle AED (Fig. 10). Modules of the second half are directed down and they are spread over another triangular fields represented, e.g., by the triangle $\mathrm{ABC}$.

Vertices of six tetrahedron modules located around a single hexagonal field are connected by means of tension members, directions of which meet at one Node M located in the center of this hexahedron. This type of spatial structure shown in Fig. 10 is called the $\mathrm{VA}(\mathrm{TH})$ No2 tension-strut structure and has to be appropriately pre-stressed, but it is not necessary to apply a perimeter compression ring $(\mathrm{R})$.

All systems of this group have nodes located at 


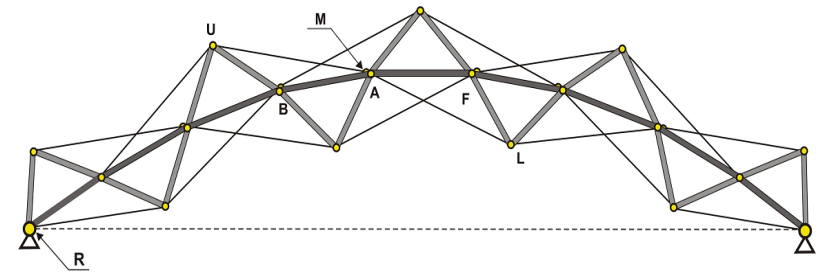

(a)

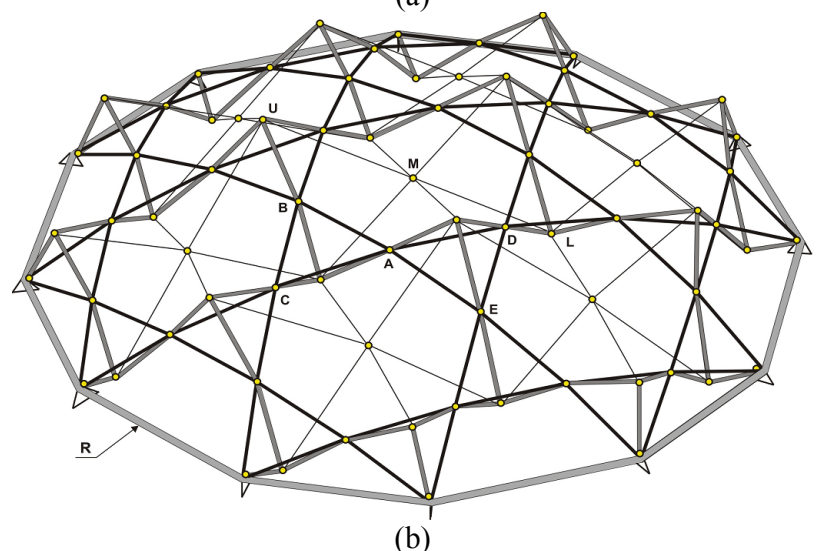

Fig. 10 General schemes of arrangement of component parts in space of the VA(TH)No2 tension-strut structure: (a) scheme of vertical cross-section; (b) view of the geodesic form of this tension-strut structure.

three levels, but they can be considered as special form of the double-layer tension-strut structure. Members of cladding can be put in several different ways between selected members of that structure. The assumed structural formula makes it possible to give an optional shape to the cover designed by means of these structures, which can also be spaced over optional forms of the base projections. Therefore, one can expect that roofs constructed by application of this group of structural systems may obtain interesting architectonic forms.

Geodesic domes, invented by Walter Bauersfeld and popularized by the professional activity of Fuller [18], are of spectacularly interesting geometric forms, but design and construction of them require application of advanced techniques, especially regarding methods of the precise determination of lengths of all members of this complex type of a spatial structure. Formian gives a wide set of the ready useful functions making processes of the complex mathematician calculations very effective, fast and relatively easy. Two special functions play significant role in the determination of numerical models of various shapes of the geodesic structures. They are quite complex and that is why descriptions of their structures are also complex $[19,20]$. The function called "polymation" allows the mapping of faces, edges and vertices of assumed forms of the basic polyhedrons and creating other polyhedral configurations according to the assumed pattern of the structural system of the dome cover (Fig. 11a).

The specific function "tractation" is applied to projections of selected objects mostly from the basic polyhedron to the designed type of the dome surface (Fig. 11b). Both these functions are integrally, mutual bounded together and their correct application is not an easy process because it needs a set of specially prepared parameters. In spite of the mentioned complexity of both key functions, the procedure of defining numerical models of geodesic domes by application of Formian has significant advantages in comparison to other types of the computer aided design processes.

The VA(TH)No2 tension-strut structure has numerous advantageous features and that is why it can be applied for various useful purposes including the support structures of geodesic domes, which can obtain very large clear spans. Numerical model of an exemplary geodesic form of this structural system is determined by means of Program 4 in Appendix D. Scheme of arrangement of component parts of the

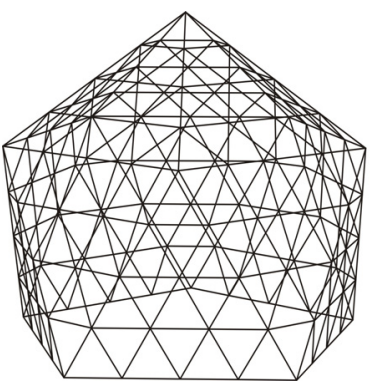

(a)

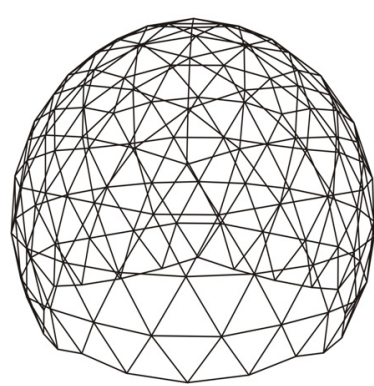

(b)
Fig. 11 Visual representation of basic stages of design of a single-layer geodesic dome spaced above the 15 upper faces of icosahedron: (a) visual example of application of the "polymation" function; (b) result of execution of the "tractation" function in process of defining numerical model of a single-layer geodesic structure. 


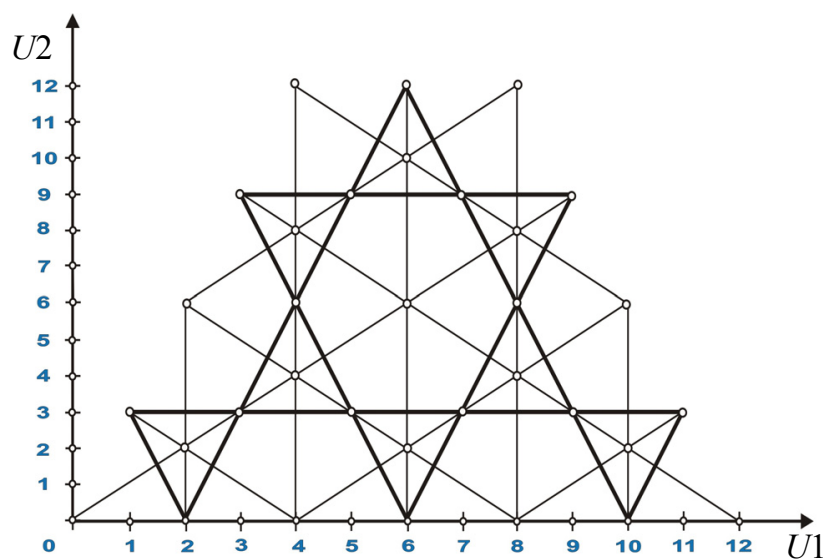

Fig. 12 Arrangement of component parts in space of the VA(TH)No2 tension-strut structure applied for preparing Program 4.

VA(TH)No2 tension-strut structure, shown in Fig. 12, was used in the process of preparation of this program.

The Program 4 defines numerical model of geodesic form of the $\mathrm{VA}(\mathrm{TH}) \mathrm{No} 2$ tension-strut structure and its suitable graphical visualization is presented in Fig. 13.

The geodesic structure of this object is planned above the 15 upper faces of the icosahedron assumed as the basic polyhedron for the Formian's "polymation" function and the "tractation" function. The Formian's program defining numerical model of this structure is rather long and, because of complexity of these above mentioned main functions, it needs some short explanations. It has been prepared for the even numbers of subdivisions controlled by parameter " $m$ " put in Row d1. A set of other geometric parameters is presented in Rows $\mathrm{d} 2-\mathrm{d} 5$ and in Row $\mathrm{d} 27$. The "polymation" function is applied three times in Rows d32-d35, where numerical modes of appropriate components of the $\mathrm{VA}(\mathrm{TH}) \mathrm{No} 2$ tension-strut structure are defined. The whole structural configuration located around 15 faces of the basic polyhedron is determined in Row d36 and then it is projected by means of the "tractation" function, placed in Row $\mathrm{d} 37$, onto the appropriate spherical parts of the designed geodesic dome cover.

In order to precisely recognize the way of the force transmission inside space of the VA(TH)No2 tension-strut structure under various loads applied in the long period of time, it was proposed to apply this structural system as a support structure of the geodesic dome (Fig. 13), designed as the main building the Centrum GEO planned for the Wroclaw University of Technology, in Poland (Figs. 14 and 15).

The Centrum GEO shall be located on the left bank of Odra River, in front of the current main campus in the close distance to the historic center of the city Wroclaw [21]. The diameter of the dome is rather small, because it is nearly $32 \mathrm{~m}$, and this magnitude follows from the urban restrictions for this down town area. In the top part of the building, it is proposed to locate a planetarium, which can be arranged also as a kind of the multipurpose hall for various types of events

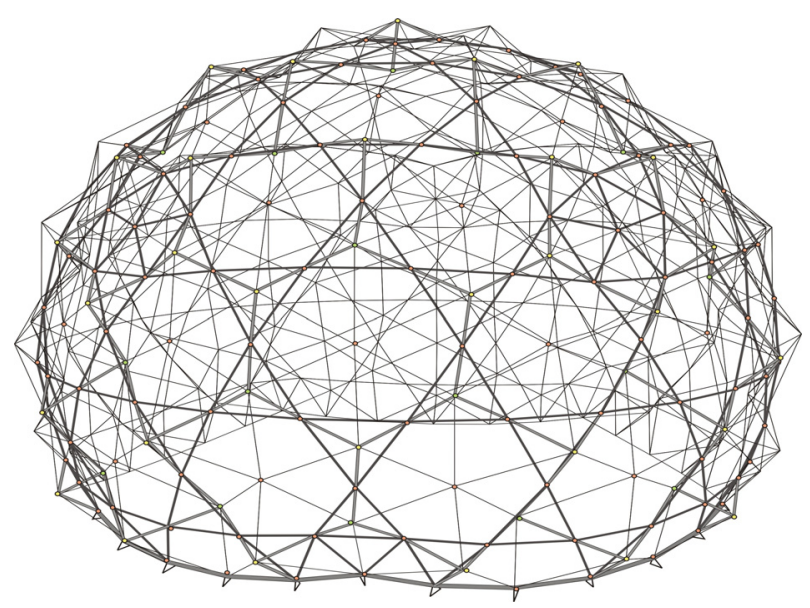

Fig. 13 Geodesic form of the VA(TH)No2 tension-strut structure determined by means of Program 4.

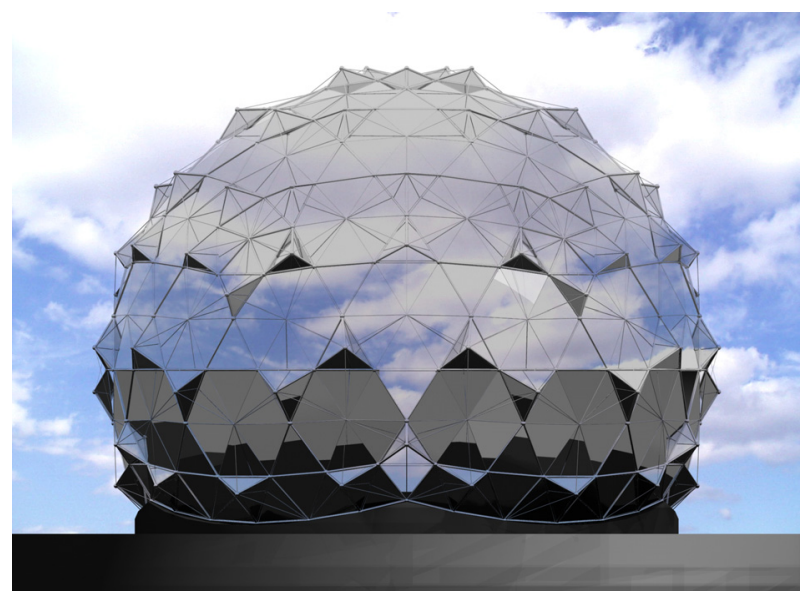

Fig. 14 Elevation of the designed geodesic dome structure with a suitable glass panels as the cladding system. 


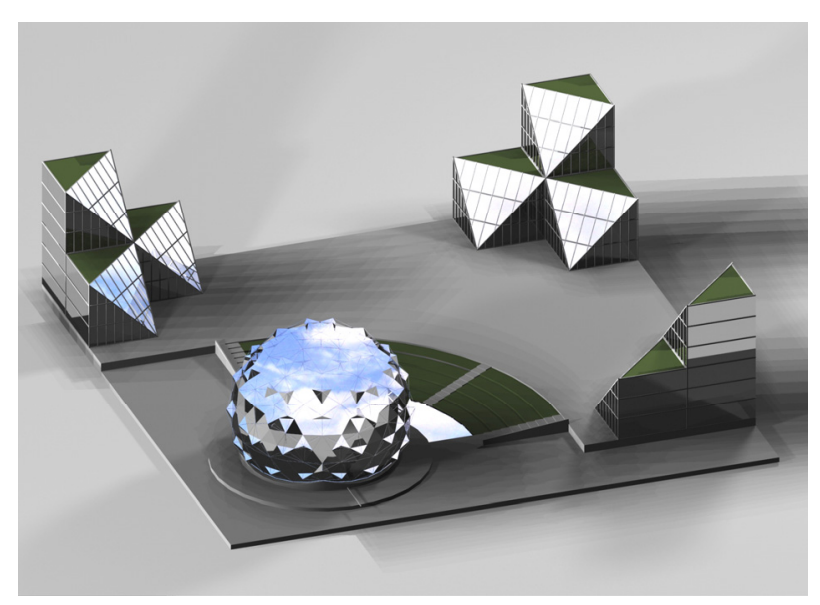

Fig. 15 General view of the proposed GEO Center.

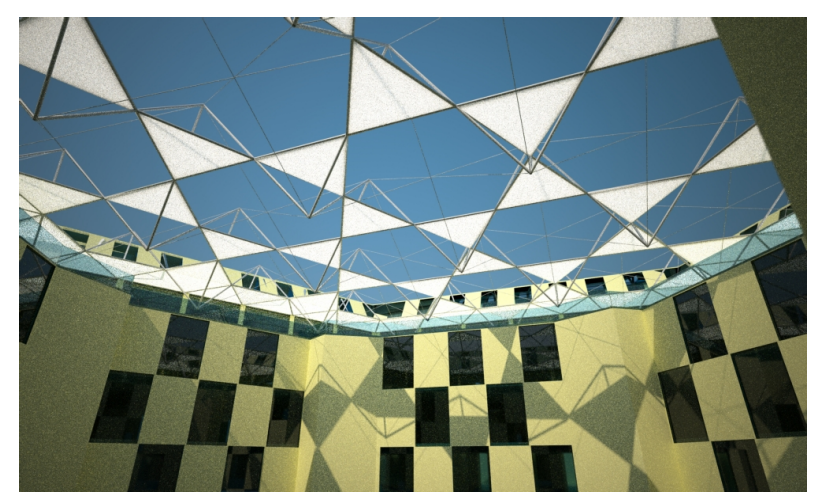

Fig. 16 Example of application of VA(TH)No2 structure as a flat form of the roof cover.

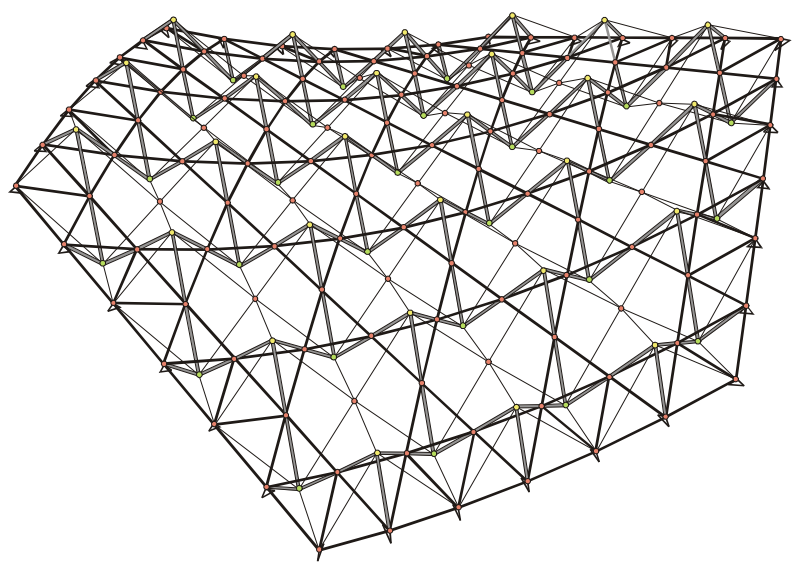

Fig. 17 Example of a hyperbolic paraboloid form of a roof designed by means of the VA(TH)No2 structure.

taking place at the university. Stories containing lecture rooms, labs and research spaces are located below. In the basement, the wind tunnel and modeling workshops are planned. The geodesic form of the VA(THA)No2 structure was planned as the support structure for testing in long terms various of the cladding systems of the main building of the Centrum GEO.

\subsection{Examples of Other Forms of the VA(TH)No2 Tension-Strut Structure}

Specific arrangement of tetrahedron modules around the triangular-hexagonal grid located in the middle-layer causes that the VA(TH)No2 tension-strut structure has advantageous structural and architectonic features, what makes it possible to apply it as a bearing structure of a flat cover (Fig. 16), or of the more complex shapes of roofs (Fig. 17), also including covers having optional forms and spaced over optional shapes of the base projections. Design of such complex forms of the roof covers is faster and easier due to application of suitable numerical models of them defined in Formian. These models can be fluently changed and adapted, at each stage of the design, to the current needs of the investment process.

\section{Conclusions}

The numerical models of structural systems defined in the programming language Formian determine precisely the way of arrangement of component parts in the spaces of these systems. These models do not define the statuses of particular members by making difference between, e.g., tension and compression members. The essential point of these models is to define positions of nodes and to determine the way of mutual connections between them into space of the designed structural systems. These models can be relatively easily transformed by an optional set of assumed parameters and they are compatible to other computer softwares, e.g., Abacus or Lusas, due to which they can be the bases for comprehensive structural analyses and also be applied for preparing architectonic visualizations. That is why numerical models defined in Formian make easier the cooperation between architects and engineers and can enormously accelerate the whole design process not only of systems of the roof structures. 
The proposed structural systems can testify that the structural formula of the tension-strut systems applied in an appropriate way can give in result the innovative structural and architectonic solutions. One could expect that this formula can be applied also in the design procedures of certain types of the retractable roof covers in the future.

\section{References}

[1] Nooshin, H. 1984. Formex Configuration Processing in Structural Engineering. New York: Elsevier Science Publishers.

[2] Nooshin, H., Disney, P., and Yamamoto, C. 1993. Formian. Brentwood: Multi-science Publishing.

[3] Zienkiewicz, O. C., and Taylor, R. L. 2000. The Finite Element Method. Oxford: Butterworth-Heinemann.

[4] Makowski, Z. S. 1981. Analysis, Design and Construction of Double-Layer Grid. London: Applied Science Publishers.

[5] Makowski, Z. S. 1985. Analysis, Design and Construction of Braced Barrel Vaults. New York: Elsevier Applied Science Publishers.

[6] Nooshin, H., and Disney, P. 2000. "Formex Configuration Processing I." International Journal of Space Structures 15 (1): 1-52.

[7] Nooshin, H., and Disney, P. 2001. "Formex Configuration Processing II." International Journal of Space Structures 16 (1): 1-56.

[8] Nooshin, H., and Disney, P. 2002. "Formex Configuration Processing III." International Journal of Space Structures 17 (1): 1-50.

[9] Hoffmann, I. S. 1999. "The Concept of Pellevation for Shaping of Structural Forms." Ph.D. thesis, University of Surrey.

[10] Allen, E., Zalewski, W., and Boston Structures Group. 2010. Form and Forces. Designing Efficient, Expressive Structures. Hoboken: John Wiley \& Sons.

[11] Robbin, T. 1996. Engineering a New Architecture. New Haven: Yale University Press.
[12] Geiger, D. H., Stefaniuk, A., and Chen, D. 1986. "The Design and Construction of Two Cable Domes for the Korean Olympics." Presented at IASS (International Association for Shell and Spatial Structure) Symposium on Shells, Membranes and Space Frames, Osaka.

[13] Rębielak, J. 1999. "Cable Dome Shaped on the Ground of the $\{\mathrm{T}-\mathrm{T}\}$ Double-Layer Space Structure. Example of Formian's Application in Creation of Numerical Model of a Structure." In Proceedings of Lightweight Structures in Civil Engineering, 86-7.

[14] Rębielak, J. 2004. "Numerical Models of Chosen Types of Dome Structures." Journal of Mathematics \& Design 4 (1): 239-49.

[15] Rębielak, J. 2005. Shaping of Space Structures. Examples of Applications of Formian in Design of Tension-Strut Systems. Wroclaw: Oficyna Wydawnicza Politechniki Wroclawskiej (Publishing House of Wrocław University of Technology).

[16] Rębielak, J. 2003. "The Concept of the Triangular-Hexagonal Tension-Strut Structure." In Proceedings of Symposium of the International Association for Shell and Spatial Structures and the Asia Pacific Conference on Shell and Spatial Structures, New Perspectives for Shell and Spatial Structures, 184-5.

[17] Rębielak, J. 2006. "Numerical Modeling in the Design Processes of Architectonic Structures." In Proceedings of the 10th World Multi-conference on Systemics, Cybernetics and Informatics, 261-6.

[18] Fuller, R. B. 1975. Synergetics: Explorations in the Geometry in Thinking. New York: McMillan.

[19] Champion, O. C. 1997. "Polyhedric Configuration." Ph.D. thesis, University of Surrey.

[20] Nooshin, H., Disney, P., and Champion, O. C. 1997. "Computer-Aided Processing of Polyhedric Configuration, beyond the Cube." In The Architecture of Space Frames and Polyhedra, edited by Gabriel, J. F. New York: John Wiley \& Sons, 343-84.

[21] Rębielak, J. 2012. "Numerical Methods in Modeling of Space Structures. Forms of Roof Covers." Archivolta 56 (4): 64-71. (in Polish)

\section{Appendix A: Program 1.}

a1. $\mathrm{m}=14 ;\left({ }^{*}\right)$ Number of subdivisions along the U1 direction(*)

a2. $\mathrm{n}=14 ;(*)$ Number of subdivisions along the U2 direction $(*)$

a3. $T o p 1=\operatorname{rinid}(\mathrm{m}, \mathrm{n}+1,2,2) \mid[0,0,1 ; 2,0,1]$;

a4. $T$ op $2=\operatorname{rinid}(m+1, n, 2,2) \mid[0,0,1 ; 0,2,1]$;

a5. TOP=Top1\#Top2;

a6. $\operatorname{Low} 1=\operatorname{rinid}(\mathrm{m}-1, \mathrm{n}, 2,2) \mid[1,1,0 ; 3,1,0]$;

a7. Low2=rinid $(m, n-1,2,2) \mid[1,1,0 ; 1,3,0]$;

a8. $\mathrm{LOW}=$ low1\#low2;

a9. Unit $=\{[0,0,1 ; 1,1,0],[2,0,1 ; 1,1,0],[0,2,1 ; 1,1,0],[2,2,1 ; 1,1,0]\}$; 
a10. $W e b=\operatorname{rinid}(m, n, 2,2) \mid$ Unit;

a11. StructP $=$ TOP\#LOW\#Web;

a12. use \&,vm(2), vt(2),

$\operatorname{vh}(0,-24,46,0,0,0,0,0,1)$

a13. draw StructP; $(*)$ see Fig. $3 \mathrm{a}(*)$

$<>$

a14. clear;

a15. $\operatorname{DomeS}=\operatorname{capel}(1, \mathrm{~m}, \mathrm{n}, 25,3) \mid \mathrm{Struct} P$;

a16. use \&, vm(2), vt(2), $\operatorname{lw}(0.2), \mathrm{c}(1,1), \mathrm{vh}(0,-14,26,0,0,0,0,0,1)$;

a17. draw DomeS; $(*)$ see Fig. $3 \mathrm{~b}(*)$

Appendix B: Program 2.

b1. $\mathrm{n}=3 ;(*)$ Subdivisions in the U3 direction $(*)$

b2. $\mathrm{m}=24 ;(*)$ Subdivisions in the U2 direction $(*)$

b3. $\mathrm{R}=18 ;(*)$ Sphere radius for the upper layer $(*)$

b4. $P P Z=[R, 0,0 ; R-1,0,0] ;(*)$ Vertical post $(*)$

b5. $\mathrm{PZW}=\operatorname{rin}(2, \mathrm{~m}, 2) \mid\{[\mathrm{R}, 1,0 ; \mathrm{R}, 1,1],[\mathrm{R}-1,0,0 ; \mathrm{R}, 1,1],[\mathrm{R}, 1,1 ; \mathrm{R}-1,2,0]\}$;

b6. $\mathrm{a}=\mathrm{PPZ \# PZW}$

b7. $\mathrm{P} 1=\operatorname{lam}(2,1) \mid\{[\mathrm{R}-1,0,1 ; \mathrm{R}, 1,1],[\mathrm{R}, 0,2 ; \mathrm{R}, 1,1],[\mathrm{R}-1,0,1 ; \mathrm{R}, 0,2],[\mathrm{R}, 0,2 ; \mathrm{R}-1,1,2]\}$;

b8. $\mathrm{P} 2=\{[\mathrm{R}-1,0,1 ; \mathrm{R}-1,2,1],[\mathrm{R}, 1,1 ; \mathrm{R}, 3,1],[\mathrm{R}, 0,2 ; \mathrm{R}, 2,2],[\mathrm{R}-1,1,2 ; \mathrm{R}-1,3,2]\}$;

b9. $\mathrm{PP} 1=\mathrm{P} 1 \# \mathrm{P} 2$;

b10. $\mathrm{np}=\mathrm{n}+1$;

b11. $\mathrm{n} 2=\mathrm{np} / 2$;

b12. Band $1=\operatorname{rinit}(\mathrm{m}, \mathrm{n} 2,2,2) \mid \mathrm{PP} 1$;

b13. $\mathrm{DDA}=\operatorname{tran}(2,1)|\operatorname{tran}(3,1)| \mathrm{PP} 1$;

b14. Band $2=\operatorname{rinit}(\mathrm{m}, \mathrm{n} 2-1,2,2) \mid \mathrm{DDA}$;

b15. EndRing $=\operatorname{tran}(3, \mathrm{n})|\operatorname{rin}(2, \mathrm{~m}, 2)|\{[\mathrm{R}, 0,1 ; \mathrm{R}, 1,2],[\mathrm{R}, 1,2 ; \mathrm{R}, 2,1],[\mathrm{R}-1,1,1 ; \mathrm{R}, 1,2],[\mathrm{R}, 1,2 ; \mathrm{R}, 3,2]\}$;

b16. $A=$ pex $\mid P P Z \# P Z W \# B$ and $1 \#$ Band2\#EndRing;

b17. $\operatorname{Pan} 1=\{[\mathrm{R}, 0,2 ; \mathrm{R}, 1,1 ; \mathrm{R}, 2,2],[\mathrm{R}, 2,2 ; \mathrm{R}, 3,1 ; \mathrm{R}, 1,1]\}$;

b18. Panel1=rinit $(\mathrm{m} / 2, \mathrm{n} 2,2,2) \mid \operatorname{Pan} 1$;

b19. $\operatorname{Pan} 2=\operatorname{ref}(3,2) \mid \operatorname{Pan} 1$;

b20. Panel $2=\operatorname{rinit}(\mathrm{m} / 2, \mathrm{n} 2-1,2,2) \mid \operatorname{Pan} 2$;

b21. Panel $3=\operatorname{rin}(2, \mathrm{~m} / 2,2) \mid[\mathrm{R}, 3,1 ; \mathrm{R}, 1,1 ; \mathrm{R}, 1,0]$;

b22. EndPanel $=\operatorname{tran}(3, \mathrm{n}-1)|\operatorname{rin}(2, \mathrm{~m} / 2,2)|\{[\mathrm{R}, 0,2 ; \mathrm{R}, 1,3 ; \mathrm{R}, 2,2],[\mathrm{R}, 2,2 ; \mathrm{R}, 1,3 ; \mathrm{R}, 3,3]\}$;

b23. Panel=Panel1\#Panel2\#Panel3\#EndPanel;

b24. $\mathrm{B}=$ Panel\#A;

b25. $\mathrm{XSP}=\mathrm{bt}(1,0.5,3) \mid \mathrm{B}$;

b26. Dome $=\mathrm{bs}(1,360 / \mathrm{m}, 5 / \mathrm{n}) \mid \mathrm{XSP}$;

b27. use \&, vt(2), $\operatorname{lw}(0.25), \mathrm{vm}(2), \mathrm{c}(1,1), \mathrm{c}(3,39), \mathrm{vh}(200,300,-220,0,0,0,0,0,1)$;

b28. draw Dome; (*)see Fig. 7(*)

Appendix C: Program 3.

c1. $n=2 ;(*)$ Number of concentric hoops $(*)$

c2. $\mathrm{m}=18 ;(*)$ Subdivisions along the U2 $\left(^{*}\right)$

c3. $\mathrm{RL}=0 ;(*) 3^{\text {rd }}$ coordinate of the lower layer $(*)$

c4. RL1 $=2 * 0.288675135 ;(*)$ Third coordinate of the 1 st node $(*)$

c5. RL $2=2 * 0.577350269 ;(*)$ Third coordinate of the vertex nodes $(*)$

c6. $\mathrm{RU}=2 * 0.866025404 ;(*)$ Third coordinate of the upper layer $(*)$

c7. Pasmol=rin $(2, \mathrm{~m}, 4) \mid\{[3,2, \mathrm{RU} ; 3,6, \mathrm{RU}],[3,6, \mathrm{RU} ; 3,4, \mathrm{RL}],[3,4, \mathrm{RL} ; 3,2, \mathrm{RU}],[3,4, \mathrm{RL} ; 3,8, \mathrm{RL}],[3,8, \mathrm{RL} ; 3,6, \mathrm{RU}],[3,4, \mathrm{RL} ; 6,4, \mathrm{RU}],[3$,

2,RU;6,4,RU],[6,4,RU;3,6,RU]\};

c8. Pasmo2 $=\operatorname{tran}(2,-2)|\operatorname{tran}(1,3)|$ Pasmo1;

c9. Ring $1=\operatorname{rin}(2, \mathrm{~m}, 4) \mid[6,0, \mathrm{RU} ; 6,4, \mathrm{RU}]$;

c10.KR1 $=\{[3,2, \mathrm{RU} ; 4,4, \mathrm{RL} 2],[4,4, \mathrm{RL} 2 ; 3,4, \mathrm{RL}],[4,4, \mathrm{RL} 2 ; 3,6, \mathrm{RU}],[4,4, \mathrm{RL} 2 ; 2,8, \mathrm{RL} 2]\}$;

c11. $K R 2=\operatorname{tran}(2,4)|\operatorname{ref}(1,3)| K R 1$;

c12. $K R=K R 1 \# K R 2$;

c13. $\mathrm{TKR} 1=\operatorname{rin}(2, \mathrm{~m} / 2,8) \mid \mathrm{KR}$;

c14. $\mathrm{TKR} 2=\operatorname{tran}(2,-2)|\operatorname{tran}(1,3)| \mathrm{TKR} 1$;

c15. $\mathrm{P} 1=\operatorname{rin}(1, \mathrm{n} / 2,3) \mid \mathrm{TKR} 1 \#$ Pasmo1;

c16. $\mathrm{P} 2=\operatorname{rin}(1, \mathrm{n} / 2,3) \mid \mathrm{TKR} 2 \#$ Pasmo2;

c17. $n 4=3 * n-3$; 
c18. Ring $=\operatorname{tran}(2,2)|\operatorname{tran}(1, \mathrm{n} 4)| \operatorname{Ring} 1$;

c19. $S T R A=P 1 \# P 2 \#$ Ring;

c20. $\operatorname{Str}=\operatorname{tran}(1,2) \mid \mathrm{STRA}$;

c21. $S T R B=b t(1.0,0.25,0.75) \mid S t r ;$

c22. $\mathrm{STR} 1=\mathrm{bp}(1,20) \mid \mathrm{STRB}$;

c23. DomeZZ=capel $(1,0,0,22,2) \mid \mathrm{STR} 1$;

c24. use \&, vt(2), vm(2), $\operatorname{lw}(0.08), \mathrm{c}(1,1), \mathrm{c}(3,39), \mathrm{vh}(-69,28,42,0,0,0,0,0,1)$;

c25. draw DomeZZ; $(*)$ see Fig. $8(*)$

Appendix D: Program 4.

d1. $\mathrm{m}=6 ;\left(^{*}\right)$ Subdivision of icosahedron edges $\left(^{*}\right)$

d2. $s=1 / 3 *$ sqrt 3 ;

d3. $\mathrm{U} 1=1.63299316 ;\left({ }^{*}\right) 3 \mathrm{rd}$ coordinate for upper layer $(*)$

d4. $\left.\mathrm{M} 2=0.0 ; *^{*}\right) 3$ rd coordinate for middle layer $(*)$

d5. $\mathrm{L} 3=-1.63299316 ;\left(^{*}\right) 3$ rd coordinate for lower layer $(*)$

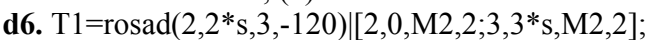

d7. TP1=genic $\left(1,2, \mathrm{~m} / 2, \mathrm{~m} / 2,4,6^{*} \mathrm{~s}, 2,-1\right) \mid \mathrm{T} 1$;

d8. $\mathrm{T} 2=\operatorname{rosad}(4,4 * \mathrm{~s}, 3,-120) \mid[3,3 * \mathrm{~s}, \mathrm{M} 2,2 ; 5,3 * \mathrm{~s}, \mathrm{M} 2,2]$;

d9. $\mathrm{TP} 2=$ genic $\left(1,2, \mathrm{~m} / 2-1, \mathrm{~m} / 2-1,4,6^{*} \mathrm{~s}, 2,-1\right) \mid \mathrm{T} 2$;

d10. $\mathrm{TG} 1=\operatorname{rosad}(2,2 * \mathrm{~s}, 3,-120) \mid[2,0, \mathrm{M} 2,2 ; 2,2 * \mathrm{~s}, \mathrm{U} 1,1]$;

d11. $\mathrm{TGW} 1=$ genic $(1,2, \mathrm{~m} / 2, \mathrm{~m} / 2,4,6 * \mathrm{~s}, 2,-1) \mid \mathrm{TG} 1$;

d12. $\mathrm{TG} 1=\operatorname{rosad}(2,2 * \mathrm{~s}, 3,-120) \mid[2,0, \mathrm{M} 2,2 ; 2,2 * \mathrm{~s}, \mathrm{U} 1,1]$;

d13. TGW1=genic $(1,2, \mathrm{~m} / 2, \mathrm{~m} / 2,4,6 * \mathrm{~s}, 2,-1) \mid \mathrm{TG} 1$;

d14. $\mathrm{TG} 1 \mathrm{~b}=\operatorname{rosad}(2,2 * \mathrm{~s}, 3,-120) \mid[0,0, \mathrm{M} 2,2 ; 2,2 * \mathrm{~s}, \mathrm{U} 1,1]$;

d15. TbGW1=genic $\left(1,2, \mathrm{~m} / 2, \mathrm{~m} / 2,4,6^{*} \mathrm{~s}, 2,-1\right) \mid \mathrm{TG} 1 \mathrm{~b}$;

d16. $\mathrm{N} 1=\{[0,0, \mathrm{M} 2,2],[2 * \mathrm{~m}, 0, \mathrm{M} 2,2],[\mathrm{m}, 3 * \mathrm{~m} * \mathrm{~s}, \mathrm{M} 2,2]\}$;

d17. $\mathrm{TbGWL}=\operatorname{lux}(\mathrm{N} 1) \mid \mathrm{TbGW} 1$;

d18. TD $2=\operatorname{rosad}(4,4 * \mathrm{~s}, 3,-120) \mid[3,3 * \mathrm{~s}, \mathrm{M} 2,2 ; 4,4 * \mathrm{~s}, \mathrm{~L} 3,3]$;

d19. TDP $2=$ genic $(1,2, \mathrm{~m} / 2-1, \mathrm{~m} / 2-1,4,6 * \mathrm{~s}, 2,-1) \mid \mathrm{TD} 2$;

d20. TD $2 b=\operatorname{rosad}(4,4 * \mathrm{~s}, 3,-120) \mid[4,0, \mathrm{M} 2,2 ; 4,4 * \mathrm{~s}, \mathrm{~L} 3,3]$;

d21. TDP $2 \mathrm{~b}=$ genic $(1,2, \mathrm{~m} / 2-1, \mathrm{~m} / 2-1,4,6 * \mathrm{~s}, 2,-1) \mid \mathrm{TD} 2 \mathrm{~b}$;

d22. TRnr2A=TP1\#TP2\#TGW1\#TDP2\#TbGWL\#TDP2b;

d23. $\mathrm{EdPs}=\operatorname{rosad}(\mathrm{m}, \mathrm{m} * \mathrm{~s}, 3,120) \mid\left\{[2,0, \mathrm{M} 2,2 ; 0,0, \mathrm{M} 2,2],[1,3 * \mathrm{~s}, \mathrm{M} 2,2 ; 0,0, \mathrm{M} 2,2],\left[2,2 *_{\mathrm{s}}, \mathrm{U} 1,1 ; 0,0, \mathrm{M} 2,2\right]\right\}$;

d24. Seg $2 s=T R n r 2 A \# E d P s$;

d25. $\mathrm{PA}=\operatorname{rin}(1, \mathrm{~m}-2,2) \mid[2,0, \mathrm{M} 2,2 ; 4,0, \mathrm{M} 2,2]$;

d26. $\mathrm{TTT}=\mathrm{Seg} 2 \mathrm{~s} \# \mathrm{TRnr} 2 \mathrm{~A}$;

d27. ws $3=0.6 ;\left(^{*}\right)$ Decreasing along $\mathrm{U} 3$ direction $(*)$

d28. FaceP1 $=$ bt $(1,1$, ws 3$) \mid$ TTT;

d29. $\mathrm{Rg}=18 ;(*)$ Sphere radius for upper layer $(*)$

d30. $\mathrm{Rm}=\mathrm{Rg}-\mathrm{U} 1 *$ ws $3 ;(*)$ Radius for middle layer $(*)$

d31. $\mathrm{RL}=\mathrm{Rg}-2 * \mathrm{U} 1 * \mathrm{ws} 3 ;(*)$ Radius for lower layer $(*)$

d32. $\mathrm{G} 1=\operatorname{pol}(1,5, '[1-15],,[3,4 ; 1, \mathrm{Rg} ; 2, \mathrm{Rm} ; 3, \mathrm{RL}],[0,0 ; 2 * \mathrm{~m}, 0],[0,0 ; 2 * \mathrm{~m}, 0],[0,0 ; 2 * \mathrm{~m}, 0]) \mid \mathrm{FaceP} 1$;

d33. Edge $=\operatorname{rin}(1, \mathrm{~m}, 2) \mid[0,0, \mathrm{M} 2,2 ; 2,0, \mathrm{M} 2,2]$;

d34. $\left.\mathrm{G} 2=\operatorname{pol}(2,5, '[21-25]]^{\prime},[3,4 ; 1, \mathrm{Rg} ; 2, \mathrm{Rm} ; 3, \mathrm{RL}],[0,0 ; 2 * \mathrm{~m}, 0],[0,0 ; 2 * \mathrm{~m}, 0],[0,0 ; 2 * \mathrm{~m}, 0]\right) \mid$ Edge;

d35. $\mathrm{G} 1=\operatorname{pol}\left(1,5,{ }^{\prime}[1-15],,[3,4 ; 1, \mathrm{Rg} ; 2, \mathrm{Rm} ; 3, \mathrm{RL}],[0,0 ; 2 * \mathrm{~m}, 0],[0,0 ; 2 * \mathrm{~m}, 0],[0,0 ; 2 * \mathrm{~m}, 0]\right) \mid \mathrm{FaceP} 1$;

d36. $\mathrm{G} 3=\mathrm{G} 1 \# \mathrm{G} 2$;

d37. $\mathrm{G} 15=\operatorname{trac}([3,4,1,2,3], 1,[0,0,0, \mathrm{Rg}, 0,0,0, \mathrm{Rm}, 0,0,0, \mathrm{RL}], 4,-15) \mid \mathrm{G} 3$;

d38. use \&, vt(2), vm(2), c(1,1),c(3,39), vh(49,-28,11,0,0,0,0,0,1);

d39. draw G15; (*)see Fig. 13(*) 